Review Paper

\title{
Microplastic contamination of salt intended for human consumption: a systematic review and meta-analysis
}

\author{
Evangelos Danopoulos ${ }^{1}$ [D $\cdot$ Lauren Jenner ${ }^{1} \cdot$ Maureen Twiddy $^{1} \cdot$ Jeanette M. Rotchell ${ }^{2}$
}

Received: 1 June 2020 / Accepted: 21 October 2020 / Published online: 5 November 2020

(c) The Author(s) 2020 OPEN

\begin{abstract}
Microplastics (MPs) are an emerging contaminant ubiquitous in the environment. There is growing concern regarding potential human health effects, a major human exposure route being dietary uptake. We have undertaken a systematic review (SR) and meta-analysis to identify all relevant research on MP contamination of salt intended for human consumption. Three thousand nine hundred and nineteen papers were identified, with ten fitting the inclusion criteria. A search of the databases MEDLINE, EMBASE and Web of Science, from launch date to September 2020, was conducted. MP contamination of salt varied significantly between four origins, sea salt 0-1674 MPs $/ \mathrm{kg}$, lake salt 8-462 MPs $/ \mathrm{kg}$, rock and well salt 0-204 MPs/kg. The majority of samples were found to be contaminated by MPs. Corresponding potential human exposures are estimated to be 0-6110 MPs per year (for all origins), confirming salt as a carrier of MPs. A bespoke risk of bias (RoB) assessment tool was used to appraise the quality of the studies, with studies demonstrating moderate to low RoB. These results suggest that a series of recurring issues need to be addressed in future research regarding sampling, analysis and reporting to improve confidence in research findings.
\end{abstract}

Keywords Microplastics $\cdot$ Food $\cdot$ Salt $\cdot$ Human consumption $\cdot$ Systematic review $\cdot$ Meta-analysis

\section{Introduction}

\subsection{Rationale}

Microplastics (MPs) have been identified in the environment in varying concentrations and compositions. MPs are found in sea water [1-3], sediments $[4,5]$, soil $[6,7]$, the atmosphere $[8,9]$, as well as in food $[10,11]$ and drinking water [12-14]. Therefore, MPs appear to be abundantly present in the environment and humans are constantly exposed to them. The effects of MPs that are currently being investigated arise from the plastics' primary components (polymers) or the additives used to enhance their attributes (plasticizers), such as bisphenol A, which has already been proven [15] to be toxic to humans. MPs can also act as transporting vectors. Plastic has been shown to adsorb and absorb persistent, bio-accumulative and toxic substances which can later be leeched from it [16-18]. Finally, MPs have proven to be a good substrate to be colonized by microorganisms, effectively transporting them and dispersing them into new environments $[19,20]$. Nanoplastics present a somewhat different behaviour to larger MPs resulting from their ability to cross biological membranes possibly delivering substances to different locations; they might become cellular vectors due to their nanoscale, thus transporting substances into cells [21].

Although it remains to be shown whether the effects of MPs on human health are significant or not, there is clearly

Electronic supplementary material The online version of this article (https://doi.org/10.1007/s42452-020-03749-0) contains supplementary material, which is available to authorized users.

Evangelos Danopoulos, hyen7@hyms.ac.uk| ${ }^{1}$ Hull York Medical School, University of Hull, Allam Medical Building, Hull HU6 7RX, UK. ${ }^{2}$ Department of Biological and Marine Sciences, University of Hull, Hull HU7 6RX, UK. 
a strong need to urgently evaluate their prevalence in the environment $[22,23]$. The first step towards understanding their significance for humans is in establishing the exposure routes and quantifying exposures. One of the major proposed exposure routes is via the food web through dietary exposure [24-28].

In recent years, significant evidence has been accumulated for the presence of MPs in food and drinking water, with several published reviews [3,29-32]. However, to our knowledge, this is the first SR and meta-analysis focusing on salt. None of the existing reviews have used the methodology and methods [33] on which SRs and meta-analyses are based on to synthesize their findings in a standardized qualitative or quantitative way.

The added value of a SR is that the underlying methodology promotes transparency, reliability and reproducibility in all the steps of the review, guided by the protocol which is designed and published before its execution [33, 34]. The goal of meta-analysis is not only to synthesize data from identical or similar studies but to broaden our understanding of a subject by expanding the base of the included studies and investigating patterns, trends and relationships [35]. The basic merit of executing the main functions of meta-analysis is that a summary of two or more studies provides a better estimate than either individual study alone [35].

The aim of this SR was to establish the MP contamination levels of salt intended for human consumption based on current knowledge using meta-analysis and statistical summary. Further aim was to model and quantify human exposure levels via ingestion of salt in the general population. At the same time, the body of literature was assessed in a narrative analysis in terms of quality in a standardized way employing a bespoke, robust tool assessing all aspects of study design, execution and reporting, in order to recognize existing scientific limitations and formulate proposals for future research.

\section{Methods}

\subsection{Protocol and registration}

The SR follows a protocol published in PROSPERO (PROSPERO 2019, Registration number: CRD42019145290), available from: https://www.crd.york.ac.uk/prospero/displ ay_record.php?ID=CRD42019145290 which was created before the execution of the review. The protocol outlines in detail the rationale for the SR as well as the methodological and analytical approach that was used.

\subsection{Eligibility criteria}

The eligibility criteria were set down in the protocol of the review. Only descriptive and analytic observational study designs (not experimental) are included since the focus of the review is on uncontrolled environmental exposures [36]. "Uncontrolled" in this context refers to not conducting an experiment under controlled conditions, not to the use of control samples [37].

\subsubsection{Inclusion}

Only primary, peer-reviewed studies are included. Other reviews and/or reports that were discovered during the search were used to check and validate our searches by comparing our results to their reference lists. No time limit on publication date was set, and all databases were searched from launch date to 10 July 2019 . The searches were repeated on the 10 September 2020 to include the most recently published papers. Although the term MPs was introduced by Thompson et al. [38], studies that used more descriptive terms were eligible to be included. The definition used for MPs was: particles of plastic material of a size up to $5 \mathrm{~mm}$; the definition includes nanoplastics which are on the nanometre scale $(\mathrm{nm})[21,39]$. More robust definitions for MPs have been proposed more recently [40,41], but this broader definition was used to ensure the inclusion of all relevant scientific literature.

Only studies that report on food samples as defined by Regulation (EC) No 178, 2002 were included: "any substance or product, whether processed, partially processed or unprocessed, intended to be, or reasonably expected to be ingested by humans. 'Food' includes drink, chewing gum and any substance, including water, intentionally incorporated into the food during its manufacture, preparation or treatment" ([42], p. 2).

Studies that used one of the following four validated processes for the identification of MPs were included: Fourier-transform infrared spectroscopy (FT-IR), Raman spectroscopy (RM), pyrolysis gas chromatography/mass spectrometry (Pyr-GC-MS) and scanning electron microscopy plus energy-dispersive X-ray spectroscopy (SEM/ EDS). The use of a validated method to identify the composition of the particles and the use of procedural blank samples was considered imperative for all the included studies, as this confirms studies are measuring the same thing $[43,44]$. Studies must have used procedural blank samples to quantify the contamination or to validate that the samples had not been contaminated after their collection. No geographical limits were placed on sampling locations, and all sampling procedures are included. For the meta-analysis part of the SR only, studies that report 
specific abundance/concentrations of MPs were included. All measuring units are included.

\subsubsection{Exclusion}

Commentaries, opinion pieces, proceedings of conferences, editorials and non-peer-reviewed reports were excluded. In addition, studies were excluded if they report on food samples that do not conform to the definition for "food" [42] or have not reported the process for the identification of MPs, or used a process outside the four highlighted. Any study that does not explicitly report the use of procedural blanks to validate quality assurance of post-collection processes were excluded. Articles that are not published in the English language were also excluded.

\subsection{Information sources}

The following online databases/sources were searched: MEDLINE (OVID interface, 1946 onwards), EMBASE (OVID interface, 1974 onwards). Medical Subject Headings (MeSH) and vocabulary thesaurus tools were used for both sources. The Web of Science core collection (Web of Science, 1900 onwards) was also searched as a multidisciplinary source. The last search was run on the 10 September 2020. In addition, the reference lists of the reviews that were discovered were searched, as well as the reference lists of relevant reports, which have already been published. Where appropriate, authors of papers were contacted in order to obtain missing information and data from published studies.

\subsection{Search}

An initial scoping review identified 3541 papers, using a search strategy maximized for sensitivity rather than specificity. The results informed the strategy for the full review which was first developed for MEDLINE and EMBASE (OVID interface) using free text and $\mathrm{MeSH}$, and then, the syntax was adapted for the Web of Science interface. Search terms included: microplastic, nanoplastic, plastic/, micro*, fiber*, food contamination, salt. Separate search strategies were devised for the interfaces OVID and Web of Science. The full search strategy for MEDLINE (OVID) and for Web of Science can be found in Online Resource (OR) 1, Section 1.

\subsection{Study selection}

The study selection assessment process was conducted in a standardized manner. EndNote (X 9.2) software was used to extract and manage citations that were identified through the search strategy. Screening questions were developed with screening at two levels. An initial screening of titles and abstracts was conducted independently by two reviewers (ED and $L J$ ) according to the inclusion/exclusion criteria. Discrepancies between the two reviewers were resolved by a third-party arbitrator $(J R)$, who is an expert in the field. The level of the interrater agreement was $90 \%$, Cohen's $k: 0.34$, indicating a fair strength of agreement between the two reviewers [45].

For the studies that met the inclusion criteria, full papers were downloaded for the second level (full text) screening, which was undertaken by ED. Reasons for excluding studies were recorded (see OR 1, Section 2). The second reviewer screened $20 \%$ of the full text studies in order to validate the process. The level of the inter-rater agreement for the second level screening was $100 \%$, Cohen's $k$ : 1 . The second level screening process also identified the studies to be included in the meta-analysis and those to be included in the statistical summary/narrative analysis.

\subsection{Data extraction}

The data extraction process used a form developed, used and validated by a scoping review. For each of the included studies, the following information was extracted: sampling (geographic location of the sampling site/s, date of sampling, sampling method), sample characteristics (sample kind and type, number of samples), sample analysis (sample replicates, MPs extraction procedure, visual identification method, composition identification method, percentage of sample which underwent composition identification method, library used for spectral analysis, percentage match index for polymer identification), results of procedural blank samples and the results of the analysis (identified type of polymer, MPs' content). When data were not reported in a usable form, the corresponding author of each paper was contacted in order to obtain the primary data. A maximum of three emails were sent to the corresponding author. Where additional information was not provided by the authors, papers were only included in the statistical summary/narrative SR and were excluded from the meta-analysis. During the data collection process, specific attributes of the data were examined (e.g. sample $n$, sample type) in order to avoid duplicate inclusion of the same data. Where duplicates were found, only the first publication was included.

\subsection{Risk of bias in individual studies}

Existing risk of bias (RoB) tools was not appropriate due to the focus and nature of this SR [46]. In order to achieve a standardized way of critically appraising the studies, a bespoke tool was developed for assessing risk of bias, based on guidelines set by the Centre for Reviews and 
Dissemination [34] for SRs of adverse effects. The quality of reporting section was developed according to the STROBE Statement checklist [47] regarding items that should be included in reports of observational studies, and the recommendations of the Agency for Healthcare Research and Quality U.S. Department of Health and Human Services [48]. In addition, principles laid down by the Environmental Risk of Bias Tool [49] regarding evidence in environmental science were taken into consideration, and adapted from the Cochrane Collaboration's tool [50] for assessing RoB in randomized trials.

The assessment tool/checklist does not use scales to assess the RoB (see OR 2, Table S1). For each entry in the checklist, a judgement was made, supported by a specific rationale [51]. For each of the entries, a question was formulated to prompt a response to support decision making. Assessment was based on predefined guidelines as specified in the RoB tool explanation/elaboration section (see OR 2) and was conducted independently by two reviewers (ED and $\mathrm{JL}$ ) in order to minimize errors, avoid the introduction of personal misconceptions and verify the effectiveness of the RoB tool [33]. Agreement between the two assessors was $100 \%$. The rating of the studies for each entry, domain and overall study was: high risk, low risk or unclear RoB. RoB assessment was carried out both on the study and on specific outcome level. The results of the assessment were used to inform both the qualitative and the quantitative synthesis.

\subsection{Summary measures}

The primary outcome was the presence of MPs in the sample and a quantitative measure of it (if available). For the meta-analysis, the focus was the MP content of the sample, specifically, the size of the sample ( $n$ ), the mean value, the standard deviation (SD) and/or the range of MP content in each type of sample in each study. Additional information of interest was the methodological details surrounding the extraction of the particles from the sample as well as the composition identification process.

\subsection{Synthesis of results}

Different units of measurement for MP content were used across the studies. All different units were extracted, and an attempt was made to standardize the units, where appropriate, and the necessary data were available. In studies where the mean value was not provided but the individual data for the samples were available, values were calculated using the standard formulae for mean and standard variation. To pool the results of different samples in the same studies, formulae for combining groups proposed by Higgins et al. [51] were used. The units used in the outcomes of the meta-analysis were MPs per volume or mass or individual of sample.

Although the minimum number of studies required for meta-analysis is two [35], a small number of included studies can limit the strength of the results. This limitation was explored throughout the meta-analysis [52]. For the quantitative synthesis of the results from different studies, a meta-analysis model was used $[53,54]$. The effect estimate for each study was calculated by weighing their results using the inverse of the variance method and fitting random-effects models $[55,56]$. The results of the meta-analysis are presented as a summary of the mean effect (content) with a $95 \%$ confidence interval and $p$ value. The $t^{2}$ estimator that was used for all the models is the DerSimonian-Laird, which has been extensively used in random-effects modelling $[57,58]$. The assessment of statistical heterogeneity was achieved by comparing the outcomes of the studies visually using Forest plots, looking at the overlap of the confidence intervals, and tested statistically using the Higgins $I^{2}$ test and $\mathrm{Chi}^{2}$ (Q Statistic) $[59,60]$. To check if the data are normally distributed, a method proposed by Altman and Bland [61] was used. Subgroup analysis employing either a fixed-effects (plural) model (mixed-effects model) or a random effects model was adopted [56] in order to compare characteristics of the sample or the studies that might influence heterogeneity (type, geographical origin, etc.). All the studies are also reported in a statistical summary of effect combined with a systematic narrative analysis [34]. Regarding the statistical summary of effect, when the range was not stated explicitly, the minimum and maximum reported MP contents were used. When the results were expressed on a different mass scale, these were homogenized into the same scale for ease of comparison. Methodological heterogeneity was assessed in terms of the overall design of the study, focusing on sample type, and the method used for the particle extraction from the samples.

The overall assessment of the certainty of the evidence for each study is based on the five considerations posed by the GRADE framework [53] in combination with the Environmental-GRADE tool developed by Bilotta et al. [49].

\subsection{Risk of bias (RoB) across studies}

Publication bias was assessed using funnel plots. In order to investigate the possibility of missing information, precision of the effect estimate was investigated [62]. To do so, a funnel plot and the Egger's test [63] were used, recognizing that the latter test only picks up bias in small studies. 


\section{Results}

\subsection{Study selection}

The search strategy produced 2467 citations after duplicates were removed. The details of the study selection procedure are illustrated in the flow diagram in Fig. 1. During the first-level screening, 2307 citations were removed based on their title and abstract as not meeting the criteria for this review. In the second level screening, the whole text of the paper was evaluated against the eligibility criteria and 112 studies were discarded; the reasons for exclusion can be found in OR 1, Section 2. Studies on three different food themes were identified: salt, seafood and drinking water. A total of 7 studies were included in this salt review (of 48 studies identified across all three food themes). When the searches were rerun, 3 more studies were included after the first and second level screening (Fig. 1), resulting in 10 studies [64-73] finally included in this systematic review. All 10 studies were included in the SR and 4 in the meta-analysis.

\subsection{Study characteristics}

Study characteristics for the salt studies are presented in OR2, Table S2. The design of all the studies was observational (non-analytic) [36]. Their aim was to examine the prevalence of MPs in commercial salt in specific countries or globally. The outcomes are presented as average content of MPs per mass ( $\mathrm{g}$ or $\mathrm{kg}$ of sample) $(n=6)$ and/ or range of MPs per mass $(n=10)$. In terms of the salt origin, four different sources/procedures were considered. In total, $n=164$ different salt brands were analysed across the ten studies: $n=110$ sea salt, $n=15$ rock salt, $n=10$ lake salt, $n=12$ well salt, and $n=17$ table salts of unidentified source (S2). The importance of the origin lies predominantly in the nature of the raw material itself, as well as the different procedure used to acquire it, namely evaporation or mining (rock or solution (well)) [74]. Three authors were contacted and asked for additional unpublished information but did not respond.

\subsection{Risk of bias within studies}

The studies were individually appraised using the assessment of bias tool across four domains and assigned an overall rating (Table 1). The judgement for each of the studies is recorded in the tool, accompanied by relevant

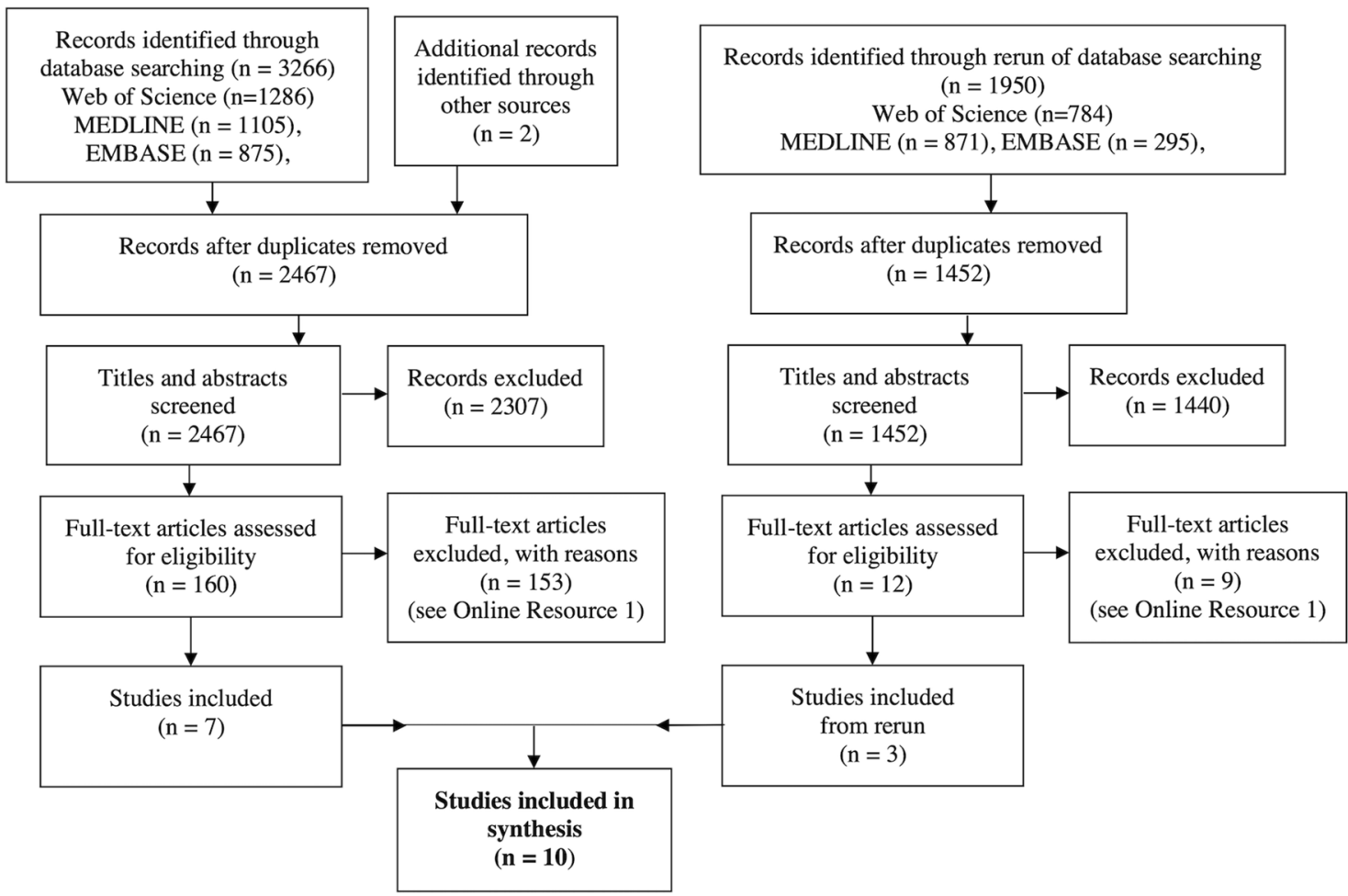

Fig. 1 PRISMA flow diagram of screening process 
text from the studies, where appropriate. Study design was found to be of low risk across all studies. The domain with the most "High RoB" was "reporting," while the domain with the most "Unclear RoB" was "analysis" (OR 2, Fig. S1). The studies with overall high RoB were those of Renzi and Blaskovic [69], Karami et al. [66] and Sathish et al. [71]. The results of the assessment are discussed and addressed in the synthesis part of the review.

\subsection{Results of individual studies}

The results of the individual studies are presented in tabular form in Table 2 grouped by sample origin where possible. The results of the Iniguez et al. [65] study were pooled for the overall sea and well salts using the Higgins et al. [51] formulae for combining groups. The results of the Lee et al. [68] were pooled for the sea salt samples using the standard mean and SD formulas. The results of the Renzi and Blaskovic [69] study were expressed in MPs/g, and they were converted to MPs/kg to facilitate comparison between studies. All studies provide ranges of MP content. Grouping the samples according to country of origin was not possible due to the lack of necessary data from some of the papers as discussed earlier.

\subsection{Synthesis of results: meta-analysis}

Only the four studies that provide sample size, mean MP content and the corresponding SD are included in the meta-analysis models (Table 3 ). The results of the study by Sathish et al. [71] were excluded from the meta-analysis as the study was rated of high RoB (Table 1), as discussed in the narrative analysis. Three studies present different results depending on the origin of the salt (sea, lake, rock, well). For the purposes of the meta-analysis, it is not reasonable to assume that the samples of different origin should be considered the same. To test this assumption statistically, a subgroup analysis using a fixed-effects (plural) model (or mixed-effects model) was conducted [56]. The results of the model are illustrated in a forest plot (Fig. 2) [75]. The forest plot shows the standardized mean difference (SMD) results for each salt type by origin (calculated weighted effect estimate) and the corresponding confidence interval (Cl 95\%) which is the range of values that we expect the true effect to lie in. The results of the random effects for salts of the same origin and the result of the fixed effect model for the four pooled different origins are also illustrated. The pooled effect for each subgroup ranges from $18.49 \mathrm{MPs} / \mathrm{kg}$ to $139 \mathrm{MPs} / \mathrm{kg}$ for rock salts and well salts, respectively. The results of the subgroup analysis regarding heterogeneity were $\mathrm{Chi}^{2}=69.83, p<0.01$ showing a statistical significance between the samples of different origin and $I^{2}=97 \%$ (high heterogeneity). Both findings support that the samples should be analysed separately according to origin. The results of the subgroup analysis are interpreted taking into consideration the small number of studies. Consequently, separate random-effects models were fitted for the sea salt samples ( $n=59$, four studies); the lake salt samples ( $n=8$, two studies); and the rock salt samples ( $n=14$, two studies). Regarding the sea
Table 1 Risk of bias (RoB) assessment of salt studies

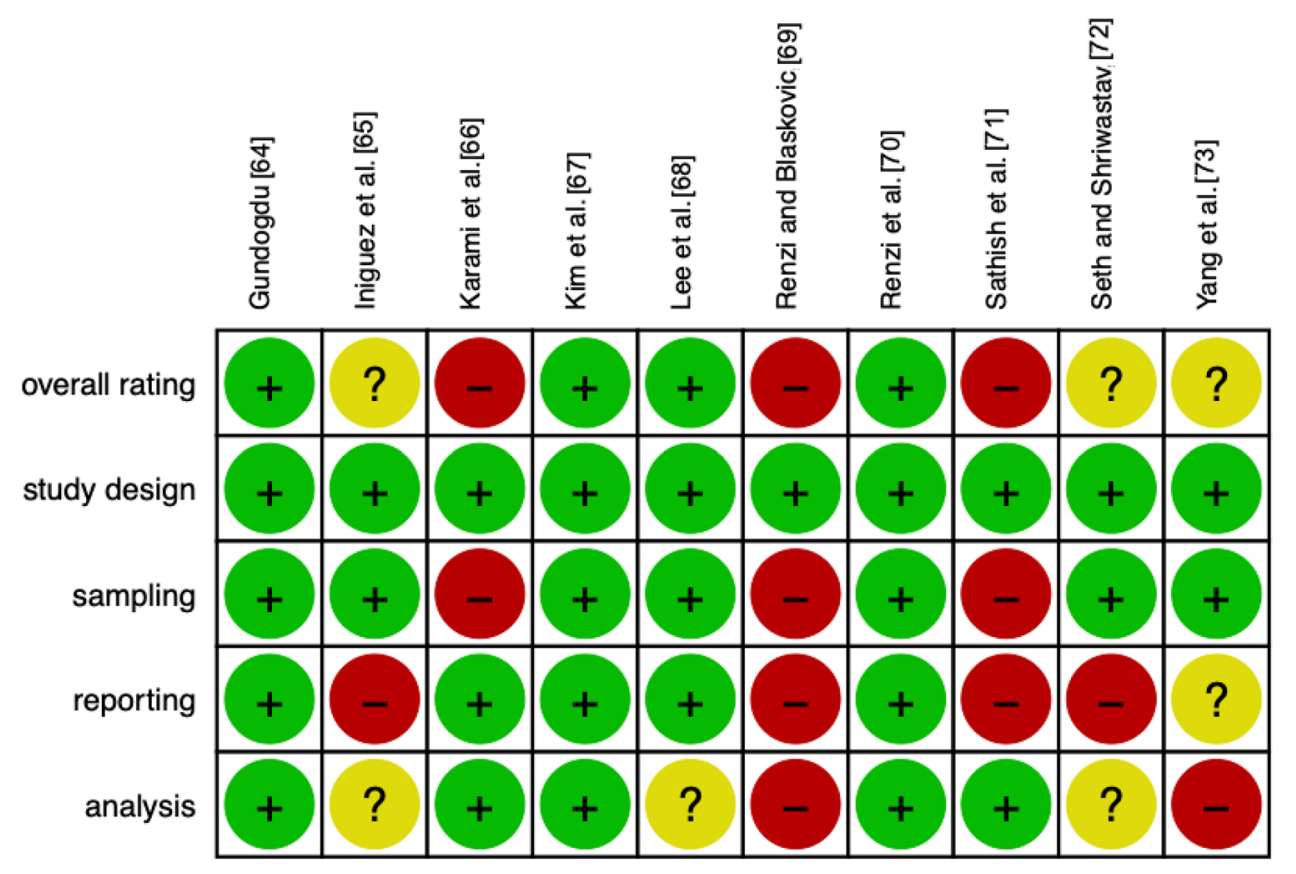

The table shows the rating for the four domains and the overall rating for each study. Red $(-)$ indicates high RoB, green (+) indicates low RoB and yellow (?) indicates unclear RoB 
salt samples, the summary mean content was $58.7 \mathrm{MPs} /$ $\mathrm{kg}(95 \% \mathrm{Cl} 14.08-103.32, p=0.0099)$. There was a high statistical heterogeneity of the pooled effect, $l^{2}=97 \%$, and $\mathrm{Chi}^{2}=100.01, p<0.0001$, as evidenced by the wide $(95 \%)$ $\mathrm{Cl}$.

A major difference between the studies, which can be seen in Table 3, is that Kim et al. [67] report a very large $S D$, while the other three studies $[64,65,68]$ report much smaller ones. This could be attributed to the fact that Kim et al. [67] had more samples and these came from multiple countries, while the other three studies use samples from one country. It should be noted that the Kim et al. [67] results are heavily influenced by an outlier, but unfortunately, the authors do not report the mean and SD when this sample is not taken into consideration. This means that results herein are also being influenced by this outlier. To statistically detect the origin of the heterogeneity, a sensitivity analysis was run by no outliers were detected. Consequently, an influence analysis was fitted the results of which can be found in Fig. S2 (OR 2). The results of both

Table 2 Salt studies MP content and polymeric composition

\begin{tabular}{|c|c|c|c|c|c|c|c|c|c|}
\hline Author (year) & $\begin{array}{l}\text { Salt sample } \\
\text { type }\end{array}$ & $n^{\mathrm{a}}$ & Mean MPs/kg & SD & Range MPs/kg & MPs size range & $\begin{array}{l}\text { Composition } \\
\text { per salt origin }\end{array}$ & $\begin{array}{l}\text { Composition all } \\
\text { samples }\end{array}$ & Shape \\
\hline \multirow{3}{*}{$\begin{array}{l}\text { Gundogdu } \\
\text { (2018) [64] }\end{array}$} & Sea & 5 & 46 & 12.6 & $16-84$ & \multirow[t]{3}{*}{$20 \mu \mathrm{m}-5 \mathrm{~mm}$} & PU (25\%) & \multirow[t]{3}{*}{ PE (22.9\%) } & \multirow[t]{3}{*}{ Fragment $>$ film } \\
\hline & Lake & 6 & 37.5 & 14.1 & $8-102$ & & PE (35.3\%) & & \\
\hline & Rock & 5 & 11.8 & 1.2 & $9-16$ & & PP (100\%) & & \\
\hline \multirow{2}{*}{$\begin{array}{l}\text { Iniguez et al. } \\
\text { (2017) [65] }\end{array}$} & Sea & 16 & 124.06 & 56.43 & $50-280$ & \multirow[t]{2}{*}{$30 \mu \mathrm{m}-3.5 \mathrm{~mm}$} & \multirow[t]{2}{*}{$n / r$} & \multirow{2}{*}{$\begin{array}{l}\text { PET (83.3\%), PP (6.7\%), } \\
\text { PE (3.3\%) }\end{array}$} & \multirow[t]{2}{*}{ Fibres } \\
\hline & Well & 5 & 139 & 26.24 & $115-185$ & & & & \\
\hline \multirow{3}{*}{$\begin{array}{l}\text { Karami et al. } \\
\text { (2017) [66] }\end{array}$} & Sea & 14 & & & \multirow[t]{3}{*}{$0-10$} & \multirow[t]{3}{*}{$160-980 \mu \mathrm{m}$} & \multirow[t]{3}{*}{$n / r$} & \multirow{3}{*}{$\begin{array}{l}\text { PP }(40.0 \%), \text { PE (33.3\%), } \\
\text { PET (6.66\%), poly- } \\
\text { isoprene/PS (6.66\%), } \\
\text { PAN (10.0\%), NY6 } \\
(3.33 \%)\end{array}$} & \multirow{3}{*}{$\begin{array}{l}\text { Fragment }>\text { fila- } \\
\text { ment }>\text { film }\end{array}$} \\
\hline & Lake & 2 & & & & & & & \\
\hline & Unidentified & 2 & & & & & & & \\
\hline \multirow[t]{3}{*}{$\begin{array}{l}\text { Kim et al. (2018) } \\
\text { [67] }\end{array}$} & Sea & 28 & 675 & 2560 & $0-13,629$ & $100 \mu \mathrm{m}-5 \mathrm{~mm}$ & $\begin{array}{l}\text { PE (35\%), PP } \\
(30 \%), \text { PET } \\
(30 \%)\end{array}$ & \multirow[t]{3}{*}{ Not specified } & \multirow[t]{3}{*}{$\begin{array}{l}\text { Frag- } \\
\text { ment }>\text { fibre }>\text { film }\end{array}$} \\
\hline & Rock & 9 & 38 & 55 & $0-148$ & & $\begin{array}{l}\text { PET (41\%), PE } \\
(26 \%), \text { PP } \\
(23 \%)\end{array}$ & & \\
\hline & Lake & 2 & 245 & 307 & $28-462$ & & $\begin{array}{l}\text { PP (47\%), PE } \\
\quad(28 \%), \text { Teflon } \\
(11 \%)\end{array}$ & & \\
\hline \multirow{2}{*}{$\begin{array}{l}\text { Lee et al. (2019) } \\
\quad[68]\end{array}$} & Sea & 10 & 9.5 & 6.1 & \multirow[t]{2}{*}{$2.5-20$} & \multirow[t]{2}{*}{$89.7-1474.9 \mu \mathrm{m}$} & \multirow[t]{2}{*}{$n / r$} & \multirow{2}{*}{$\begin{array}{l}\text { PP }(39.5 \%), \text { PE (34.9\%), } \\
\text { PS (14.0\%), polyester } \\
\text { (4.7\%), PEI (2.3\%), } \\
\text { PET (2.3\%), POM } \\
(2.3 \%)\end{array}$} & \multirow[t]{2}{*}{ Fragment $>$ fibre } \\
\hline & Rock & 1 & 12.5 & $\mathrm{n} / \mathrm{r}$ & & & & & \\
\hline \multirow{2}{*}{$\begin{array}{l}\text { Renzi and } \\
\text { Blaskovic } \\
\text { (2018) [69] }\end{array}$} & Sea, Italian & 6 & 5400 & & $1570-8230$ & $4-2100 \mu \mathrm{m}$ & \multirow[t]{2}{*}{$n / r$} & \multirow[t]{2}{*}{$\mathrm{n} / \mathrm{r}$} & \multirow{2}{*}{$\begin{array}{l}\text { Frag- } \\
\text { ment }>\text { fibre }>\text { film }\end{array}$} \\
\hline & Sea, Croatian & 5 & 28,900 & & $27,130-31,680$ & $15-4628 \mu \mathrm{m}$ & & & \\
\hline \multirow{2}{*}{$\begin{array}{l}\text { Renzi et al. } \\
\text { (2019) [70] }\end{array}$} & Sea, Italian & 6 & $n / r$ & $n / r$ & $170-320$ & \multirow[t]{2}{*}{$10-150 \mu \mathrm{m}$} & PET and PVC & \multirow[t]{2}{*}{$\mathrm{n} / \mathrm{r}$} & \multirow[t]{2}{*}{ Fibres } \\
\hline & Sea, Croatian & 5 & $n / r$ & $\mathrm{n} / \mathrm{r}$ & $70-200$ & & $\begin{array}{l}\text { PA, PP, and } \\
\text { nylon }\end{array}$ & & \\
\hline $\begin{array}{l}\text { Sathish et al. } \\
(2020)[71]\end{array}$ & Sea & 7 & 54 & 13.4 & $\begin{array}{l}35( \pm 15)-72 \\
( \pm 40)\end{array}$ & $55 \mu \mathrm{m}-2 \mathrm{~mm}$ & $\mathrm{n} / \mathrm{r}$ & $\begin{array}{l}\mathrm{PE}(51.6 \%), \mathrm{PP}(25 \%), \\
\text { polyester }(21.8 \%), \mathrm{PA}\end{array}$ & Fibre $>$ fragment \\
\hline & Well & 7 & 12 & 9.5 & $2( \pm 1)-29( \pm 11)$ & & & $(1.6 \%)$ & \\
\hline $\begin{array}{l}\text { Seth and Shri- } \\
\text { wastav (2018) } \\
\text { [72] }\end{array}$ & Sea & 8 & $n / r$ & $\mathrm{n} / \mathrm{r}$ & $\begin{array}{l}56( \pm 49)-103 \\
\quad( \pm 39)\end{array}$ & $\mathrm{n} / \mathrm{r}$ & & $\begin{array}{l}\text { Polyesters ( 61\%, PET } \\
\sim 7 \%), \text { PE ( 22\%), PA } \\
(\sim 16 \%)\end{array}$ & Fragment $>$ fibre \\
\hline $\begin{array}{l}\text { Yang et al. } \\
\text { (2015) [73] }\end{array}$ & Sea & 15 & $n / r$ & $n / r$ & $550-681$ & $45 \mu \mathrm{m}-4.3 \mathrm{~mm}$ & $\begin{array}{l}\text { PET (27.3\%), PE } \\
(20.5 \%), \text { CP } \\
(18.2 \%)\end{array}$ & $\begin{array}{l}\text { CP (39.5\%), PET } \\
\quad(16.3 \%), \text { PE (8.5\%), PB } \\
(8.5 \%)\end{array}$ & Fragment $>$ fibre \\
\hline & Lake & & $n / r$ & $n / r$ & $43-364$ & & $\begin{array}{l}\text { CP (43.2\%), PET } \\
(11.4 \%), \text { PB } \\
(11.4 \%)\end{array}$ & & \\
\hline & Rock/well & & $n / r$ & $n / r$ & $7-204$ & & $\begin{array}{l}\text { CP }(58.5 \%), \\
\text { PET }(9.8 \%), \\
\text { PB (4.9\%), PP } \\
(4.9 \%)\end{array}$ & & \\
\hline
\end{tabular}

$C P$ cellophane, NY6 nylon 6, PA polyamide, $P A N$ polyacrylonitrile, $P B$ polybutylene, $P E$ polyethylene, $P E I$ polyetherimide, $P E T$ polyethylene terephthalate, $P O M$ polyoxymethylene, $P P$ polypropylene, $P S$ polystyrene, $P U$ polyurethane, $P V C$ polyvinyl chloride

${ }^{a} n$ refers to number of brands 
Table 3 Salt studies included in the meta-analysis

\begin{tabular}{llrlll}
\hline Author (year) & Sample type & $n$ & Mean MPs/kg & SD & RoB $^{\text {a }}$ \\
\hline Gundogdu (2018) [64] & Sea & 5 & 46 & 12.6 & Low \\
& Lake & 6 & 37.5 & 14.1 & \\
& Rock & 5 & 11.8 & 1.2 & \\
Iniguez et al. (2017) [65] & Sea & 16 & 124.06 & 56.43 & Unclear \\
& Well & 5 & 139 & 26.24 & \\
Kim et al. (2018) [66] & Sea & 28 & 675 & 2560 & Low \\
& Rock & 9 & 38 & 55 & \\
Lee et al. (2019) [68] & Lake & 2 & 245 & 307 & \\
\hline
\end{tabular}

${ }^{\mathrm{a}}$ Rob risk of bias assessment
Subgroup

lake

Gundogdu [64]

Kim et al. [67]

Random effects model

$I^{2}=0 \%, \chi_{1}^{2}=0.91(p=0.34)$

rock

Gundogdu [64]

Kim et al. [67]

Random effects model

$l^{2}=51 \%, \chi_{1}^{2}=2.04(p=0.15)$

\section{sea}

Gundogdu [64]

Iniguez et al. [65]

Kim et al. [67]

Lee et al. [68]

Random effects model

$I^{2}=97 \%[95 \% ; 98 \%], \chi_{3}^{2}=100.01(p<0.01)$

well

Iniguez et al. [65]

Random effects model

not applicable

Fixed effects (plural) model

Prediction interval

$l^{2}=97 \%$ [95\%; 98\%], $\chi_{3}^{2}=69.83(p<0.01)$

\section{Standardised Mean} Difference

SMD

$37.50 \quad$ [ 26.22; 48.78]

$245.00 \quad$ [-180.47; 670.47]

37.65 [ 26.37; 48.92]

$\begin{array}{rrr}11.80 & \text { [ } 10.75 ; & 12.85] \\ 38.00 & \text { [ 2.07; } 73.93] \\ \mathbf{1 8 . 4 9} & \text { [ } \mathbf{- 3 . 9 0 ;} & \mathbf{4 0 . 8 8}]\end{array}$

$46.00 \quad[34.96 ; 57.04]$

$124.06 \quad$ [ 96.41; 151.71]

$675.00 \quad$ [-273.22; 1623.22]

$9.50 \quad$ [ $5.72 ; 13.28]$

58.70 [ 14.08; 103.32]

$139.00 \quad$ [116.00; 162.00]

139.00 [ $116.00 ; 162.00$ ]

51.03 [ $42.00 ; 60.07]$

[ $3.71 ; 101.67$ ]
Fig. 2 Subgroup analysis for all four origins of salt. The $x$ axis represents the standardized mean difference (SMD) expressed in MPs/ $\mathrm{kg}$. The vertical line is the line of null effect where MP content is 0 . The grey boxes represent the pooled effect estimate and the lines the confidence interval $(\mathrm{Cl}) 95 \%$. The size of the boxes is propor- tional to the study weight. The diamonds are the combined point estimates and $\mathrm{Cl}$ for each of the subgroups. The dotted line is the overall pooled effect for all subgroups with a corresponding diamond. The red box is the prediction interval PI 95\% 
analyses were inconclusive which led us to include all four studies. RoB was also examined in a sensitivity analysis but was similarly inconclusive.

Regarding the two lake salt studies ( $n=8$ samples), the overall content was computed at $37.65 \mathrm{MPs} / \mathrm{kg}(95 \% \mathrm{Cl}$ $26.37-48.92, p<0.0001)$. The heterogeneity is extremely low $I^{2}=0 \%$ and $\mathrm{Chi}^{2}=0.91, p=0.3393$. In this case, there is no need to explore heterogeneity further. The rock studies meta-analysis provided an overall estimate of MP content of $18.49 \mathrm{MPs} / \mathrm{kg}(95 \% \mathrm{Cl}-3.9$ to $40.88, p=0.1056)$. The heterogeneity is moderate $l^{2}=51 \%$ and $\mathrm{Chi}^{2}=2.04, p=0.1532$. Regarding $\mathrm{RoB}$, both studies in the lake and rock group were rated as "low".

\subsection{Risk of bias across studies}

In order to explore RoB across studies (publication bias), a series of funnel plots [35] were explored (Fig. S3a-c, OR 2). As can be seen in Fig. 3, the asymmetry of the distribution for all the salt studies is caused by two results in the left-hand side of the plot; these are the Kim et al. [67] study results for lake and sea salt samples. This study has already been observed to affect disproportionally the meta-analysis due to extreme size effects. The studies in the white background do not have statistically significant effect sizes. The results of the Egger's test were intercept $=4.441$ (1.501-7.381 Cl, $p=0.02264)$. The $p$ value for the Egger's test is significant which means that there is notable asymmetry in the funnel plot. The results of the Egger's test should be interpreted with caution since the number of the studies is too small $(<10)$ to draw safe conclusions.

This SR has set stringent methodological eligibility criteria that have led to a large number of studies being excluded. Studies with lower methodological rigor tend to report higher results due to overestimation of MP content.

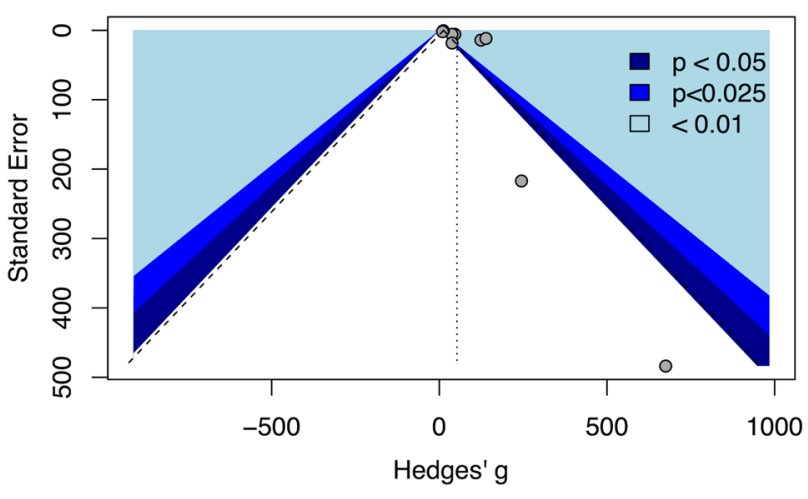

Fig. 3 Publication risk of bias funnel plot for all salt origins. Content expressed in MPs/kg salt. Dots represent individual studies. The vertical dotted line represents the pooled effect size. Diagonal lines represent pseudo $95 \%$ confidence limits
Therefore, it can be assumed that the symmetry at the bottom of the funnel plot would have been better had these studies been included, but they would also be statistically non-significant for the effect size. Hence, it is reasonable to assume that the asymmetry is not due to non-reporting bias.

\subsection{Statistical summary of effects/narrative analysis}

The effect size for the summary is the range of MP content (MPs/kg), which has been reported by all the included studies (Table 2). Sample heterogeneity, in terms of origin, is primarily addressed again by grouping the samples according to their origin (sea, lake, rock and well). Taking into consideration the ranges of MP content reported by the studies (without any weighting), the MP content is 0-31,680 MPs/kg for sea salt, $0-462 \mathrm{MPs} / \mathrm{kg}$ for lake salt, 0-204 MPs/kg for rock and for well salt (Fig. 4).

Regarding the results of MP content in sea salt, the study by Renzi and Blaskovic [69] stands out. They report mean contents of 5400 and $28,900 \mathrm{MPs} / \mathrm{kg}$ and ranges of 1570-8230 and 27,130-31,680 MPs/kg for Italian and Croatian marine salts, respectively. The range reported by Kim et al. [67] is similar (0-13,629 MPs/kg), but the mean is much lower at $675 \mathrm{MPs} / \mathrm{kg}$ salt. Kim et al. [67] also highlight that they identified one outlier sea salt sample in their analysis and reported a reduced range of 0-1674 MPs/kg when excluding it. Renzi and Blaskovic [69] state that extremely high values might be due to human error during visual particle identification and the increased level of pollution in the areas where the salt's raw material is collected. However, the lower mean content for the Italian salts is eight times higher than the closest reported mean content. This study was one of five $[65,66,68-70]$ that did not use digestion in the particle-extraction procedure and the one of the three [68-70] that did not use a densityseparation technique to separate MPs from non-polymeric particles. Their analysis protocol fails to report important information: the number of replicates they used, the results of their procedural blank samples to account for after-sampling contamination and whether the results of the procedural blanks were subtracted from the final results. In addition, they do not report the specifics around the polymer composition identification: how many particles they identified with the help of $m-F T I R$ as a fraction of their sample, the spectral library they used, the acceptance rate for a particle to be considered of polymer origin (usually set above $60 \%$ ) and it was the only study that did not report results on the polymer composition of the MPs. In the light of these reporting omissions, the results and conclusions should be interpreted with caution. In their later work [70], they identified extremely lower content of $70-320 \mathrm{MPs} / \mathrm{kg}$ of salt (in the size fraction of $10-150 \mu \mathrm{m}$ ) 
Fig. 4 MP content in salt from all origins expressed in $\log _{10}$ for ease of comparison. The points in the graph represent the mean values of MP content for the studies that report it, whiskers represent the reported ranges of MPs $/ \mathrm{kg}$. A: sea salt, B: lake salt, C: rock salt, $D$ : well salt, E: rock/well salt, $F$ : unidentified

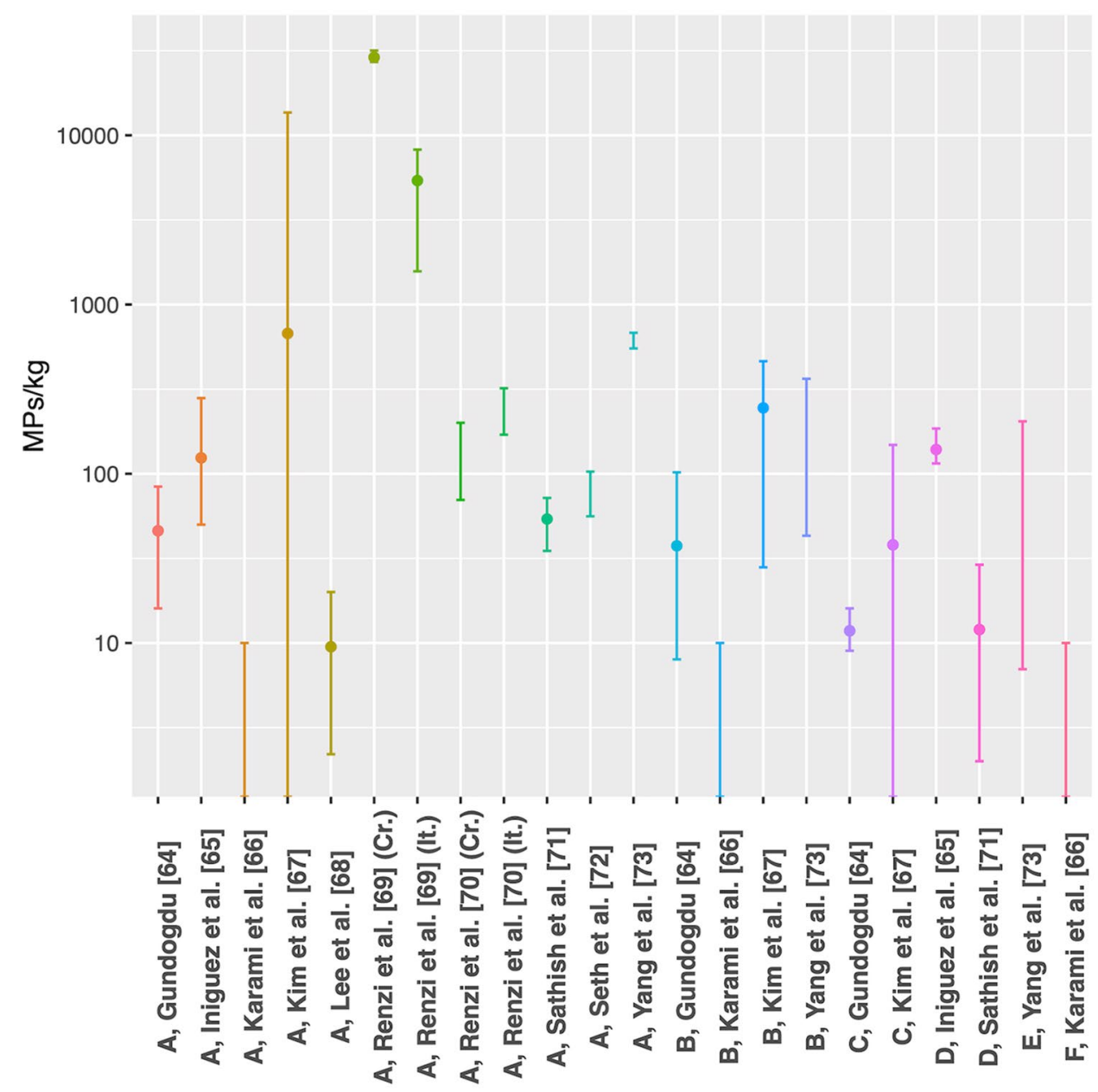

and recognize that systematic composition analysis is necessary to avoid overestimations. Kim et al. [67] also report high ranges compared to the other studies. They state that differences in the analytical processes and samples might be the cause of these variations. However, the highest difference is caused by a reported outlier sample.

At the other end of the extreme ranges, Karami et al. [66] reports a range of $0-10 \mathrm{MPs} / \mathrm{kg}$. They stated that they had a high proportion of non-identified particles (29.1\%), while a quarter of the sample was identified as pigments. This study employed a two-step filter extraction procedure, without digestion, which resulted in only a fraction of the extracted particles (size particles $>149 \mu \mathrm{m}$ ), being considered in the results. This could have led to a significant underestimation of the MP content, a limitation the authors acknowledge. The size of particles included is important because the number of MPs increases as their size decreases [75-78]. Therefore, including only smaller size MPs could affect the estimate of overall MP content disproportionally. This study did not analyse the procedural blank samples. Instead, the filters were weighed and change in their weight was used to account for post sampling contamination. This procedure is not common practice and cannot be seen as adequate in verifying the protection of their samples. Thus, we do not know if and how contamination of the samples has affected the results of this study. Similarly, the study by Sathish et al. [71] did not report any details surrounding the procedural blank samples including their results.

The studies by Renzi and Blaskovic [69], Karami et al. [66] and Sathish et al. [71] were rated as of high RoB (Table 1). It should also be noted that the results of the study by Renzi et al. [70] cannot be directly compared nor collated with the rest of the studies because the design of the study targeted the specific size fraction of 10-150 $\mu \mathrm{m}$. Removing the three studies that were rated of high RoB studies from the results as well as the outlier of the Kim et al. [67] study (as suggested by the authors [67]), the distribution of the ranges decreases (Fig. S4, OR 2), and the MP content range narrows to $0-1674 \mathrm{MPs} / \mathrm{kg}$ of sea salt.

Lake salt MP content ranges exhibit the same pattern. Karami et al. [66] and Kim et al. [67] report the lowest and highest ranges, respectively. Besides the narrowed size fraction, there is another factor that might play a part in 
the underrepresentation of MPs in the Karami et al. [66] study, which is the absence of a digestion step in the particle-extraction process which the other three studies use. Omitting this study from the results only narrows the range to 8-462 MPs/kg of lake salt. Regarding the rock and well salt studies, Yang et al. [73] present one combined result for both origins that cannot be directly compared to the result for well salt from the Iniguez et al. [65] study, while the results of the Sathish et al. [71] study are omitted due to high RoB rating (Table 1). The rest of the studies report fairly similar results.

Across the studies the minimum size of identified MP particle by the studies ranged from 4 to $160 \mu \mathrm{m}$ (Table 2) and could have been directly affected by two experimental parameters: the pore size of the filters used for the extraction of the particles and the technical abilities/limitations of the technology used for the composition identification. Filters of different pore sizes were used ranging from 0.2 to $8 \mu \mathrm{m}$, representing the minimum cut-off size, while two of the studies also used a maximum cut-off size of $>149 \mu \mathrm{m}$ [66] and $<150 \mu \mathrm{m}$ [70], as previously noted (Table S2, OR 2). FTIR and RM can analyse particles in the range of $40 \mu \mathrm{m}$ and $10 \mu \mathrm{m}$, respectively, but when they are coupled with microscopes their technical specifications are enhanced to analysing particles in the size of $10(\mathrm{~m}-\mathrm{FTIR}) \mu \mathrm{m}$ and $1 \mu \mathrm{m}$ (m-RM) [79-84]. The relationship between these parameters and the MP content is illustrated in Fig. S5a, $b$ (OR2) where we can see that there is only a weak negative trend between the size of the identified MP and the content in the samples which could be attributed to the small number of studies and other confounding parameters previously discussed. The association between the size of the measured MPs particles and their content has already been highlighted in our previous work [85]. Fragment was the most commonly discovered shape of MPs across all studies, followed by fibre (Table 2 ).

Across all the studies that analyses salt from different origins, the pattern of MP content found is that sea salts exhibit the highest content, followed by lake and then rock. This pattern can be attributed to the corresponding environmental contamination of the raw material, i.e. natural brine from a sea or lake or man-made brine from wells which is an open (and exposed) system, compared to a closed and largely protected system of underground rock salt.

There are only two studies $[65,71]$ that sampled well salt $(n=12)$ and one study [73] that sampled rock/well salt ( $n=$ unknown). Although these studies use samples that come from underground, there is a key difference between them. Well salt is derived from brine that has been artificially produced by pumping water in underground salt sources. The brine is then evaporated in open lakes or in closed circuits. The samples used in the studies by Iniguez et al. [65] and Sathish et al. [71] come from artificial brine that has been evaporated in open lakes and is therefore exposed to further environmental pollution. On the other hand, the Yang et al. [73] study does not differentiate between the two types (rock and well), and it is not possible to determine whether the salt has been exposed to environmental conditions or not. The higher MP content in the Iniguez et al. [65] study could be attributed to these processes.

In terms of polymeric composition, four studies [64, $67,70,73$ ] differentiate between salts of different origin, five studies $[65,66,68,71,72]$ do not and one study [69] does not report any results [69]. The most prevalent polymers across all studies and origins were polypropylene (PP) and polyethylene (PE), followed by polyethylene terephthalate (PET) (Table 2). The most commonly found polymer in sea salt was PE and PET, in lake salt PE and in rock/well salt PET. In addition, it is important to highlight that Yang et al. [73] included the compounds cellophane $(C P)$ and cellulose $(C L)$ in their MPs results, while the rest of the studies did not. Kim et al. [67] did considered CP but reported that this was not detected in their samples.

Five studies collected samples from one country [64, 65, 71-73] (four in the continent of Asia [64, 71-73]), and two studies $[69,70]$ described samples for two countries (both in Europe). Three studies [65-68] examined MPs salt contamination in multiple countries. Karami et al. [66] examined samples of salt produced in different eight countries but available through the Malaysian market ( $n=17$ brands). They did not attempt a comparison between countries and did not report their results in a usable form by country. Likewise, Lee et al. [68] sampled brands that were available in the Taiwanese market and possibly also coming from third counties but did not report further details. In contrast, Kim et al. [67] who also analysed salts from different countries $(n=21)$, purchased most of the samples in the countries that they were produced in $(n=17)$, thus allowing them to extrapolate to a global pattern. The study reports a comparison between Asia (1028 $\pm 3169 \mathrm{MPs} / \mathrm{kg})$ and all other continents ( $39 \pm 9 \mathrm{MPs} / \mathrm{kg}$ ), but unfortunately, they only report their results in figures which does not allow for further analysis and reproducibility. A pattern did not emerge for the MP content in salt between different countries or continents.

\subsection{Summary of evidence}

The results of the SR are presented in the summary of evidence table (Table 4) which integrates the meta-analysis, the statistical summary and the narrative analysis as well as the overall rating of the evidence according to the GRADE methodology and the E-GRADE tool $[49,53]$. 


\section{Discussion}

To our knowledge, this is the first SR addressing MP contamination of salt intended for human consumption. We have reviewed ten studies which, in total, analysed 164 different salt samples/brands coming from 28 different countries. Four studies were included in the meta-analysis, and all ten studies are included in the statistical summary of effects and narrative analysis. MPs were present in the vast majority of the examined samples from all four origins (sea, lake, rock and well), with levels varying significantly across studies from 0 to $1674 \mathrm{MPs} / \mathrm{kg}$ of salt. The studies are of moderate to low quality (Table 4). The review provides robust evidence of ubiquitous salt MPs contamination.

Narrative analysis detected a number of issues in the methodology of the studies in all stages. We explicitly appraised the quality of the existing evidence in order to

Table 4 Summary of evidence of MP content in salt intended for human consumption

\begin{tabular}{|c|c|c|c|c|}
\hline Origin & $\begin{array}{l}\text { Number } \\
\text { of studies }\end{array}$ & $\begin{array}{l}\text { Out- } \\
\text { comes }^{a}\end{array}$ & $95 \% \mathrm{Cl}$ & $\begin{array}{l}\text { Certainty } \\
\text { of the } \\
\text { evidence }^{b}\end{array}$ \\
\hline \multicolumn{5}{|c|}{ Average MPs/kg content ${ }^{c}$} \\
\hline Sea salt & 4 & 58.70 & 14.08 to 103.32 & $\begin{array}{l}\oplus \oplus \ominus \ominus \\
\text { Low }^{d}\end{array}$ \\
\hline Lake salt & 2 & 37.65 & 26.37 to 48.92 & $\begin{array}{l}\oplus \oplus \oplus \ominus \\
\text { Moderate }\end{array}$ \\
\hline Rock salt & 2 & 18.49 & -3.9 to 40.88 & $\begin{array}{l}\oplus \oplus \oplus \ominus \\
\text { Moderate }\end{array}$ \\
\hline Well salt & 1 & 139.00 & 26.24 (SD) & \\
\hline \multicolumn{5}{|c|}{ Range of MPs $/ k g$ content ${ }^{\mathrm{e}}$} \\
\hline Sea salt & 5 & 0 to 1674 & & $\begin{array}{l}\oplus \oplus \oplus \ominus \\
\text { Moderate }\end{array}$ \\
\hline Lake salt & 4 & 8 to 462 & & $\begin{array}{l}\oplus \oplus \oplus \ominus \\
\text { Moderate }\end{array}$ \\
\hline Rock/well salt & 4 & 0 to 204 & & $\begin{array}{l}\oplus \oplus \oplus \ominus \\
\text { Moderate }\end{array}$ \\
\hline
\end{tabular}

${ }^{\mathrm{a}}$ The three studies that were rated as of high RoB: Karami et al. [66], Renzi and Blaskovic [69] and Sathish et al. [71] are not included in the summary of evidence. The outlier sample of the Kim et al. [67] study is not included

${ }^{\mathrm{b}}$ All studies are upgraded due to the absence of confounders

'Meta-analysis

${ }^{\mathrm{d}}$ Due to high heterogeneity

eStatistical summary

Certainty rating symbols are according to Higgins et al. [33]: High: $\oplus \oplus \oplus \oplus$

Moderate: $\oplus \oplus \oplus \ominus$

Low: $\oplus \oplus \ominus \ominus$

Very low: $\oplus \ominus \ominus \ominus$ move forwards discussions around MPs in food intended for human consumption. Major issues concern the use of different processes for the extraction of particles from the samples and the following identification of their composition as well as poor reporting. Well-reported studies would allow for more effective comparison across the studies and increase confidence in our conclusions. In this fast developing field, consensus is needed in order to achieve consistency in how MPs are extracted [44, 86-96] what is measured $[21,40,41]$ and how it is reported [47, $48,97-99]$. Improving the quality of reporting is key to creating a more robust methodology.

According to the World Health Organization [100], the daily consumption of sodium should be less than $2000 \mathrm{mg}$ of sodium, which is roughly equivalent to $5 \mathrm{~g}$ of salt for adults ( $>16$ years old) and adjusted downwards for children according to their energy needs. The European Food Safety Authority [101] recently agreed that an intake of $2000 \mathrm{mg}$ should be the daily intake limit. Similarly, the U.S. Department of Health \& Human Services (HHS) adopting the 2015-2020 Dietary Guidelines for Americans published by the U.S. Department of Health and Human Services and U.S. Department of Agriculture [102] recommends that adults should consume less than $2300 \mathrm{mg}$ of sodium daily. However, according to WHO [103], actual consumption is estimated to be twice that level (9-12 $\mathrm{g}$ of salt per day). For the purposes of illustration, we have calculated yearly MP intake from salt of different origins using both the WHO daily recommendation of $5 \mathrm{~g}$ and an estimate of $10 \mathrm{~g}$ for the actual daily consumption (see Table 5). These results should be seen only as indicative given that adult salt consumption likely varies widely from country to country. Based on the $10 \mathrm{~g}$ estimate for daily consumption, the largest potential MPs uptake for human adults comes from salt of well origin (507.35 MPs/year), followed by sea, lake and rock (214.26, 137.42 and $67.49 \mathrm{MPs} /$ year, respectively), according to the reported MP contamination. According to the statistical summary based on a $10 \mathrm{~g}$ daily salt consumption, human exposures from the consumption of salt intended for human consumption are estimated to be in the range 0-6110 MPs per year. Note that in the statistical summary the well samples have been consolidated with the rock samples. Modelling is based on analysis of salt samples that were commercially available for human consumption and assumes no losses of MP contamination during cooking. It is expected that some portion of MP might be extracted during food preparation and cooking, thus reducing the exposure levels, but there are no available data at this point to account for it. It is recognized that this is a limitation of the calculated exposure levels and in the future they could be adjusted downwards.

A recent review by Peixoto et al. [104] on MPs pollution in commercial salts has reviewed the same studies 
Table 5 Yearly MPs uptake through the consumption of salt for adults

\begin{tabular}{|c|c|c|c|c|}
\hline & Sea salt & Lake salt & Rock salt & Well salt \\
\hline \multicolumn{5}{|l|}{$\begin{array}{l}\text { Average MPs } \\
(95 \% \text { Cl) uptake }\end{array}$} \\
\hline Recommendation for salt consumption ${ }^{b}[100]$ & $107.13 \pm 81.43$ & $68.71 \pm 20.57$ & $33.74 \pm 40.86$ & $253.68 \pm 47.89^{c}$ \\
\hline Actual salt consumption ${ }^{d}[103]$ & $214.26 \pm 162.86$ & $137.42 \pm 41.14$ & $67.49 \pm 81.72$ & $507.35 \pm 95.78^{c}$ \\
\hline \multicolumn{5}{|l|}{ Range of MPs uptake } \\
\hline Recommendation for salt consumption ${ }^{b}[100]$ & $0-3055.05$ & $14.60-843.15$ & $0-372.3$ & \\
\hline Actual salt consumption ${ }^{d}[103]$ & $0-6110.1$ & $29.20-1686.3$ & $0-744.6$ & \\
\hline
\end{tabular}

${ }^{\text {a Meta-analysis }}$

${ }^{\mathrm{b}} 5 \mathrm{~g}$ of salt per day

'Standard deviation

${ }^{\mathrm{d}} 10 \mathrm{~g}$ of salt per day

eStatistical summary

plus one study that did not meet the eligibility criteria for this SR. However, the Peixoto et al. [104] review is not systematic, nor claims to be, and does not attempt to collate the results of the studies. They report a maximum potential yearly ingestion of 36,135 particles coming from salt, which is driven by the results of the study by Renzi and Blaskovic [69] that have not been included in our analysis. Similarly, the review by Zhang et al. [32] estimates MPs human exposures reporting a maximum of $7.3 \times 10^{4}$ MPs per year which is also derived by the results of the Renzi and Blaskovic [69] study. The review by Cox et al. [3] included salt in their analysis and reported $0.11 \mathrm{MPs} / \mathrm{g}$ content, using data from four studies. One of the studies [66] Cox et al. [3] used has been omitted from our results due to methodological issues. The Cox et al. [3] review does not differentiate between salt origin in their results and do not report projected MPs consumption coming only from salt but from a range of foodstuffs. Nevertheless, the magnitude of MP content they report is similar to our review. Lee et al. [68] also included a review in their study reporting an annual intake of $537.4 \mathrm{MPs}$ ( $10.5 \mathrm{~g}$ salt per daily consumption) which is in the same range of the statistical summary results but more than two times higher from the meta-analysis results. This could be attributed to the use of descriptive statistics as opposed to the use of statistical modelling that weighs results according to the sample size and SD. The quality of the results of this SR has been improved by excluding evidence coming from studies that did not meet the a priori eligibility criteria set in our protocol, as well as, studies that were rated as of high RoB according to the RoB assessment tool (OR 2, Table S1).

Polymeric composition of MPs varied across the studies including: $P E T, P P, P E$, polyamide (PA), polyurethane (PU), etc., among others (Table 2). The most prevalent polymers were PP and PE which were also the most produced and used in the past decades [105-108] further supporting the connection between the mismanagement of plastic waste and environmental pollution.

Regarding sea salt, we would expect that the MP content would follow the level of MPs contamination in the sea or ocean of origin. However, this was not found. The limited number of studies included and methodological heterogeneity between studies may have distorted this association. Additionally, this review did not focus on detecting how the salt was contaminated but instead on the level of contamination in salt "on the shelf" ready to be consumed. In terms of country of origin, a pattern of MP content did not emerge.

\subsection{Strengths and limitations}

This is the first SR and meta-analysis that collates evidence from multiple studies to estimate the MP content in salt for human consumption to extrapolate to human MPs uptake from this specific foodstuff. It provides a robust and realistic assessment of MPs in salt by bringing together evidence from multiple studies that have been thoroughly assessed in a systematic and standardized manner. Quantification of human exposure to MPs is the first step of an informed, evidence-based risk assessment of the risk posed by this emerging risk factor. The bespoke quality assessment tool constructed for this review can be used in future reviews to assess robustness of research (OR 2, Table S1). It can also be used as a guide to inform future researchers on common issues identified in this field. A limitation of this review is that the conclusions that can be drawn are limited by the small number of studies as well as heterogeneity in the samples and the methods used by different studies. Three studies were considered as of high RoB, and they were excluded from the summary of evidence. The incomplete reporting of the results by a 
number of studies invalidated their use in the meta-analysis and in a validation process.

\section{Conclusions}

The presence of MPs in food intended for human consumption and in human stool has been documented [109]. Although the possible effects to humans are still to be explored [110-113], given the international concerns about the potential effects of MPs on human health, more research is urgently needed on the impact of MPs in salt and other foodstuffs.

From a food safety perspective, when and if MPs are proven to be agents that have the potential to cause adverse human health effects, they will be classified as food hazards. Therefore, they will be included in any food safety risk assessment, such as HACCP [114] as a possible chemical or physical risk factor, conforming to current food safety legislation [42]. Salt is included in a vast array of foodstuffs, raising the issue of MPs being transferred to different foods and acting as vehicles for the distribution of MPs, thus possibly making it a major food safety issue. Given the global nature of food consumption and the export of salt around the world, this needs investigation.

It is essential to quantify and assess the exposures from all available routes (ingestion, inhalation) and sources and then use it as a risk-assessment framework to bring together current scientific knowledge from animal studies [115-119] and human studies $[111,112,120]$ to investigate the potential causal link. This hazard characterization can then be used in conjunction with the exposure assessment to produce the risk characterization of MPs which will ultimately inform us of the likelihood that this hazard will adversely affect human health [121-124]. Further research is needed in order to establish exposure routes as well as exposure doses for a complete risk assessment of MPs [123, 125]. The outcomes of this study can be used by policy makers to address exposures to this emerging contaminant.

Acknowledgments This research is supported by a $\mathrm{PhD}$ scholarship within the "Health Inequalities and emerging environmental contaminants-Places and People" cluster funded by the University of Hull.

Authors' contributions The principal author is ED. Search strategy, data collection and analysis were designed and performed by ED. The second reviewer for the screening of studies was LJ. The assessors for the risk assessment tool were ED and LJ. The first draft of the manuscript was written by ED, and all authors commented on previous versions of the manuscript. All authors read and approved the final manuscript.

Funding This research is supported by a PhD scholarship within the "Health Inequalities and emerging environmental
contaminants-Places and People" cluster funded by the University of Hull.

Data availability All data are available in the paper and the Electronic Supplementary Material.

Code availability Software: RStudio, Version 1.2.1335. Libraries: meta (version 4.9-7), metaphor (version 2.1-0), dmetar, robvis and ggplot2.

\section{Compliance with ethical standards}

Conflict of interest The authors declare that they have no conflict of interest.

Open Access This article is licensed under a Creative Commons Attribution 4.0 International License, which permits use, sharing, adaptation, distribution and reproduction in any medium or format, as long as you give appropriate credit to the original author(s) and the source, provide a link to the Creative Commons licence, and indicate if changes were made. The images or other third party material in this article are included in the article's Creative Commons licence, unless indicated otherwise in a credit line to the material. If material is not included in the article's Creative Commons licence and your intended use is not permitted by statutory regulation or exceeds the permitted use, you will need to obtain permission directly from the copyright holder. To view a copy of this licence, visit http://creativecommons .org/licenses/by/4.0/.

\section{References}

1. Avio CG, Gorbi S, Regoli F (2017) Plastics and microplastics in the oceans: from emerging pollutants to emerged threat. Mar Environ Res 128:2-11. https://doi.org/10.1016/j.maren vres.2016.05.012

2. Barrows APW, Cathey SE, Petersen CW (2018) Marine environment microfiber contamination: global patterns and the diversity of microparticle origins. Environ Pollut 237:275-284. https ://doi.org/10.1016/j.envpol.2018.02.062

3. Cox KD, Covernton GA, Davies HL, Dower JF, Juanes F, Dudas SE (2019) Human consumption of microplastics. Environ Sci Technol 53(12):7068-7074. https://doi.org/10.1021/acs.est.9b01517

4. Bergmann $M$, Wirzberger $V$, Krumpen $T$, Lorenz $C$, Primpke $S$, Tekman MB, Gerdts G (2017) High quantities of microplastic in arctic deep-sea sediments from the HAUSGARTEN Observatory. Environ Sci Technol 51(19):11000-11010. https://doi. org/10.1021/acs.est.7b03331

5. Zhang C, Zhou H, Cui Y, Wang C, Li Y, Zhang D (2019) Microplastics in offshore sediment in the Yellow Sea and East China Sea, China. Environ Pollut 244:827-833. https://doi.org/10.1016/j. envpol.2018.10.102

6. Chae Y, An Y-J (2018) Current research trends on plastic pollution and ecological impacts on the soil ecosystem: a review. Environ Pollut 240:387-395. https://doi.org/10.1016/j.envpo I.2018.05.008

7. Liu M, Lu S, Song Y, Lei L, Hu J, Lv W, Zhou W, Cao C, Shi H, Yang X, He D (2018) Microplastic and mesoplastic pollution in farmland soils in suburbs of Shanghai, China. Environ Pollut 242:855-862. https://doi.org/10.1016/j.envpol.2018.07.051

8. Dehghani S, Moore F, Akhbarizadeh R (2017) Microplastic pollution in deposited urban dust, Tehran metropolis, Iran. Environ 
Sci Pollut Res 24(25):20360-20371. https://doi.org/10.1007/ s11356-017-9674-1

9. Wright SL, Ulke J, Font A, Chan KLA, Kelly FJ (2020) Atmospheric microplastic deposition in an urban environment and an evaluation of transport. Environ Int 136:105411. https://doi. org/10.1016/j.envint.2019.105411

10. Li J, Green C, Reynolds A, Shi H, Rotchell JM (2018) Microplastics in mussels sampled from coastal waters and supermarkets in the United Kingdom. Environ Pollut 241:35-44. https://doi. org/10.1016/j.envpol.2018.05.038

11. Teng J, Wang Q, Ran W, Wu D, Liu Y, Sun S, Liu H, Cao R, Zhao J (2019) Microplastic in cultured oysters from different coastal areas of China. Sci Total Environ 653:1282-1292. https://doi. org/10.1016/j.scitotenv.2018.11.057

12. Mintenig SM, Loder MGJ, Primpke S, Gerdts G (2019) Low numbers of microplastics detected in drinking water from ground water sources. Sci Total Environ 648:631-635. https://doi. org/10.1016/j.scitotenv.2018.08.178

13. Tong $\mathrm{H}$, Jiang $\mathrm{Q}, \mathrm{Hu} X$, Zhong X (2020) Occurrence and identification of microplastics in tap water from China. Chemosphere 252:126493. https://doi.org/10.1016/j.chemospher e. 2020.126493

14. Shruti VC, Perez-Guevara F, Kutralam-Muniasamy G (2020) Metro station free drinking water fountain - a potential "microplastics hotspot" for human consumption. Environ Pollut 261:114227. https://doi.org/10.1016/j.envpol.2020.114227

15. Gore AC, Chappell VA, Fenton SE, Flaws JA, Nadal A, Prins GS, Toppari J, Zoeller RT (2015) Executive summary to EDC-2: The Endocrine Society's second scientific statement on endocrinedisrupting chemicals. Endocr Rev 36(6):593-602. https://doi. org/10.1210/er.2015-1093

16. Hartmann NB, Rist S, Bodin J, Jensen LHS, Schmidt SN, Mayer P, Meibom A, Baun A (2017) Microplastics as vectors for environmental contaminants: exploring sorption, desorption, and transfer to biota. Integr Environ Assess Manag 13(3):488-493. https://doi.org/10.1002/ieam.1904

17. Koelmans AA, Bakir A, Burton GA, Janssen CR (2016) Microplastic as a vector for chemicals in the aquatic environment: critical review and model-supported reinterpretation of empirical studies. Environ Sci Technol 50(7):3315-3326. https://doi. org/10.1021/acs.est.5b06069

18. Seltenrich N (2015) New link in the food chain? Marine plastic pollution and seafood safety. Environ Health Perspect 123(2):A34-A41. https://doi.org/10.1289/ehp.123-A34

19. Arias-Andres $M$, Klümper U, Rojas-Jimenez K, Grossart H-P (2018) Microplastic pollution increases gene exchange in aquatic ecosystems. Environ Pollut 237:253-261. https://doi. org/10.1016/j.envpol.2018.02.058

20. Keswani A, Oliver DM, Gutierrez T, Quilliam RS (2016) Microbial hitchhikers on marine plastic debris: human exposure risks at bathing waters and beach environments. Mar Environ Res 118:10-19. https://doi.org/10.1016/j.marenvres.2016.04.006

21. GESAMP (2015) Sources, fate and effects of microplastics in the marine environment: a global assessment, vol 90. The Joint Group of Experts on Scientific Aspects of Marine Environmental Protection, Working Group 40, London

22. Alexy P, Anklam E, Emans T, Furfari A, Galgani F, Hanke G, KoeImans A, Pant R, Saveyn H, Sokull Kluettgen B (2020) Managing the analytical challenges related to micro- and nanoplastics in the environment and food: filling the knowledge gaps. Food Addit Contam 37(1):1-10. https://doi.org/10.1080/19440 049.2019 .1673905

23. Gouin T, Becker RA, Collot A-G, Davis JW, Howard B, Inawaka K, Lampi M, Ramon BS, Shi J, Hopp PW (2019) Toward the development and application of an Environmental Risk Assessment
Framework for microplastic. Environ Toxicol Chem 38(10):20872100. https://doi.org/10.1002/etc.4529

24. Bouwmeester H, Hollman PCH, Peters RJB (2015) Potential health impact of environmentally released micro- and nanoplastics in the human food production chain: experiences from nanotoxicology. Environ Sci Technol 49(15):8932-8947. https ://doi.org/10.1021/acs.est.5b01090

25. Gallo F, Fossi C, Weber R, Santillo D, Sousa J, Ingram I, Nadal A, Romano D (2018) Marine litter plastics and microplastics and their toxic chemicals components: the need for urgent preventive measures. Environ Sci Eur 30:1-14. https://doi. org/10.1186/s12302-018-0139-z

26. Karbalaei S, Hanachi P, Walker TR, Cole M (2018) Occurrence, sources, human health impacts and mitigation of microplastic pollution. Environ Sci Pollut Res 25(36):36046-36063. https://doi.org/10.1007/s11356-018-3508-7

27. Smith M, Love DC, Rochman CM, Neff RA (2018) Microplastics in seafood and the implications for human health. Curr Environ Health Rep 5(3):375-386. https://doi.org/10.1007/s4057 2-018-0206-z

28. Waring RH, Harris RM, Mitchell SC (2018) Plastic contamination of the food chain: a threat to human health? Maturitas 115:64-68. https://doi.org/10.1016/j.maturitas.2018.06.010

29. Hantoro I, Löhr AJ, Van Belleghem FGAJ, Widianarko B, Ragas AMJ (2019) Microplastics in coastal areas and seafood: implications for food safety. Food Addit Contam Part A Chem Anal Control Expo Risk Assess 36(5):674-711. https://doi. org/10.1080/19440049.2019.1585581

30. Toussaint B, Raffael B, Angers-Loustau A, Gilliland D, Kestens V, Petrillo M, Rio-Echevarria IM, Van den Eede G (2019) Review of micro- and nanoplastic contamination in the food chain. Food Addit Contam Part A Chem Anal Control Expo Risk Assess 36(5):639-673. https://doi.org/10.1080/19440 049.2019 .1583381

31. Welle F, Franz R (2018) Microplastic in bottled natural mineral water - literature review and considerations on exposure and risk assessment. Food Addit Contam Part A Chem Anal Control Expo Risk Assess 35(12):2482-2492. https://doi. org/10.1080/19440049.2018.1543957

32. Zhang Q, Xu EG, Li J, Chen Q, Ma L, Zeng EY, Shi H (2020) A review of microplastics in table salt, drinking water, and air: direct human exposure. Environ Sci Technol 54(7):3740-3751. https://doi.org/10.1021/acs.est.9b04535

33. Higgins JPT, Thomas J, Chandler J, Cumpston M, Li T, Page MJ, Welch V (2019) Cochrane handbook for systematic reviews of interventions. Version 6.0 (updated July 2019). Cochrane

34. Centre for Reviews and Dissemination (CRD) (2009) Systematic reviews: CRD's guidance for undertaking reviews in health care. Centre for Reviews and Dissemination, University of York, York, UK

35. Borenstein M (2009) Introduction to meta-analysis. Wiley, Chichester

36. Centre for Evidence-Based Medicine (2019) Study designs. https://www.cebm.net/2014/04/study-designs/. Accessed 16 Oct 2019

37. Eberhardt LL, Thomas JM (1991) Designing environmental field studies. Ecol Monogr 61(1):53-73. https://doi. org/10.2307/1942999

38. Thompson RC, Olsen Y, Mitchell RP, Davis A, Rowland SJ, John AWG, McGonigle D, Russell AE (2004) Lost at sea: Where is all the plastic? Science 304(5672):838. https://doi.org/10.1126/ science.1094559

39. GESAMP (2016) Sources, fate and effects of microplastics in the marine environment: part two of a global assessment, vol 93. The Joint Group of Experts on Scientific Aspects of Marine Environmental Protection, Working Group 40, London, UK 
40. Frias JPGL, Nash R (2019) Microplastics: finding a consensus on the definition. Mar Pollut Bull 138:145-147. https://doi. org/10.1016/j.marpolbul.2018.11.022

41. Hartmann NB, Huffer T, Thompson RC, Hassellov M, Verschoor A, Daugaard AE, Rist S, Karlsson T, Brennholt N, Cole M, Herrling MP, Hess MC, Ivleva NP, Lusher AL, Wagner M (2019) Are we speaking the same language? Recommendations for a definition and categorization framework for plastic debris. Environ Sci Technol 53(3):1039-1047. https://doi. org/10.1021/acs.est.8b05297

42. Council Regulation (EC) No 178 (2002) Of the European Parliament and of the Council of 28 January 2002 laying down the general principles and requirements of food law, establishing the European Food Safety Authority and laying down procedures in matters of food safety

43. Lusher AL, Welden NA, Sobral P, Cole M (2017) Sampling, isolating and identifying microplastics ingested by fish and invertebrates. Anal Methods 9(9):1346-1360. https://doi. org/10.1039/c6ay02415g

44. Silva $A B$, Bastos $A S$, Justino $C I L$, da Costa JAP, Duarte $A C$, Rocha-Santos TAP (2018) Microplastics in the environment: challenges in analytical chemistry. A review. Anal Chim Acta 1017:1-19. https://doi.org/10.1016/j.aca.2018.02.043

45. Landis JR, Koch GG (1977) The measurement of observer agreement for categorical data. Biometrics 33(1):159-174. https://doi.org/10.2307/2529310

46. Page MJ, McKenzie JE, Higgins JPT (2018) Tools for assessing risk of reporting biases in studies and syntheses of studies: a systematic review. BMJ Open 8(3):e019703. https://doi. org/10.1136/bmjopen-2017-019703

47. von Elm E, Altman DG, Egger M, Pocock SJ, Gøtzsche PC, Vandenbroucke JP (2007) The strengthening the reporting of observational studies in epidemiology (STROBE) statement: guidelines for reporting observational studies. Ann Intern Med 147(8):573-577. https://doi.org/10.7326/0003-4819147-8-200710160-00010

48. West S, King V, Carey T, Lohr K, McKoy N, Sutton S, Lux L (2002) Systems to rate the strength of scientific evidence: summary. AHRQ Evidence Report Summaries. Agency for Healthcare Research and Quality (US), Rockville, MD

49. Bilotta G, Milner A, Boyd I (2014) Quality assessment tools for evidence from environmental science. Environ Evid 3:14. https://doi.org/10.1186/2047-2382-3-14

50. Higgins JPT, Altman DG, Gøtzsche $P C$, Jüni $P$, Moher $D$, Oxman AD, Savović J, Schulz KF, Weeks L, Sterne JAC (2011) The Cochrane Collaboration's tool for assessing risk of bias in randomised trials. BMJ 343:d5928. https://doi.org/10.1136/ bmj.d5928

51. Higgins JPT, Green SP (2011) Cochrane handbook for systematic reviews of interventions. Wiley, Chichester, UK

52. Konstantopoulos S, Hedges LV (2019) Statistically analyzing effect sizes: fixed- and random-effects models. In: Hedges LV, Cooper H, Valentine JC (eds) The handbook of research synthesis and meta-analysis. Russell Sage, New York

53. Cooper HM (2016) Research synthesis and meta-analysis: a step-by-step approach, 5th edn. SAGE Publications, Thousand Oaks

54. Veroniki AA, Jackson D, Viechtbauer W, Bender R, Bowden J, Knapp G, Kuss O, Higgins JPT, Langan D, Salanti G (2016) Methods to estimate the between-study variance and its uncertainty in meta-analysis. Res Synth Methods 7(1):55-79. https://doi.org/10.1002/jrsm.1164

55. Chen DG, Peace KE (2013) Applied meta-analysis with R. CRC Press, Boca Raton, FL
56. Harrer M, Cuijpers P, Furukawa T, Ebert D (2019) Doing metaanalysis in R: a hands-on guide. https://doi.org/10.5281/ zenodo. 2551803

57. DerSimonian R, Laird N (1986) Meta-analysis in clinical trials. Control Clin Trials 7(3):177-188. https://doi. org/10.1016/0197-2456(86)90046-2

58. DerSimonian R, Laird N (2015) Meta-analysis in clinical trials revisited. Contemp Clin Trials 45(Pt A):139-145. https://doi. org/10.1016/j.cct.2015.09.002

59. Higgins JPT, Thompson SG (2002) Quantifying heterogeneity in a meta-analysis. Stat Med 21(11):1539-1558. https://doi. org/10.1002/sim.1186

60. Higgins JPT, Thompson SG, Deeks JJ, Altman DG (2003) Measuring inconsistency in meta-analyses. BMJ 327(7414):557-560. https://doi.org/10.1136/bmj.327.7414.557

61. Altman DG, Bland JM (1996) Statistics Notes: detecting skewness from summary information. BMJ 313(7066):1200. https:// doi.org/10.1136/bmj.313.7066.1200

62. Liberati A, Altman DG, Tetzlaff J, Mulrow C, Gøtzsche PC, loannidis JPA, Clarke M, Devereaux PJ, Kleijnen J, Moher D (2009) The PRISMA statement for reporting systematic reviews and meta-analyses of studies that evaluate healthcare interventions: explanation and elaboration. BMJ 339:b2700. https:// doi.org/10.1136/bmj.b2700

63. Egger M, Smith GD, Schneider M, Minder CJB (1997) Bias in meta-analysis detected by a simple, graphical test. BMJ 315(7109):629-634. https://doi.org/10.1136/bmj.315.7109.629

64. Gundogdu S (2018) Contamination of table salts from Turkey with microplastics. Food Addit Contam Part A Chem Anal Control Expo Risk Assess 35(5):1006-1014. https://doi. org/10.1080/19440049.2018.1447694

65. Iniguez ME, Conesa JA, Fullana A (2017) Microplastics in Spanish table salt. Sci Rep 7(1):8620. https://doi.org/10.1038/s4159 8-017-09128-x

66. Karami A, Golieskardi A, Choo CK, Larat V, Galloway TS, Salamatinia $B$ (2017) The presence of microplastics in commercial salts from different countries. Sci Rep 7:46173. https://doi. org/10.1038/srep46173

67. Kim JS, Lee HJ, Kim SK, Kim HJ (2018) Global pattern of microplastics (MPs) in commercial food-grade salts: sea salt as an indicator of seawater MP pollution. Environ Sci Technol 52(21):12819-12828. https://doi.org/10.1021/acs.est.8b04180

68. Lee H, Kunz A, Shim WJ, Walther BA (2019) Microplastic contamination of table salts from Taiwan, including a global review. Sci Rep 9:10145. https://doi.org/10.1038/s41598-019-46417-z

69. Renzi M, Blaskovic A (2018) Litter \& microplastics features in table salts from marine origin: Italian versus Croatian brands. Mar Pollut Bull 135:62-68. https://doi.org/10.1016/j.marpo Ibul.2018.06.065

70. Renzi M, Grazioli E, Bertacchini E, Blaskovic A (2019) Microparticles in table salt: levels and chemical composition of the smallest dimensional fraction. J Mar Sci Eng 7(9):310. https:// doi.org/10.3390/jmse7090310

71. Sathish MN, Jeyasanta I, Patterson J (2020) Microplastics in salt of Tuticorin, southeast coast of India. Arch Environ Contam Toxicol 79(1):111-121. https://doi.org/10.1007/s00244-020-00731 $-0$

72. Seth CK, Shriwastav A (2018) Contamination of Indian sea salts with microplastics and a potential prevention strategy. Environ Sci Pollut Res 25(30):30122-30131. https://doi.org/10.1007/ s11356-018-3028-5

73. Yang D, Shi H, Li L, Li J, Jabeen K, Kolandhasamy P (2015) Microplastic pollution in table salts from China. Environ Sci Technol 49(22):13622-13627. https://doi.org/10.1021/acs.est.5b03163

74. EUsalt (2019) Salt production. https://eusalt.com/salt-produ ction. Accessed 18 Nov 2019 
75. Fagerland MW (2015) Chapter 12 - Evidence-based medicine and systematic reviews. In: Laake $\mathrm{P}$, Benestad HB, Olsen BR (eds) Research in medical and biological sciences, 2nd edn. Academic, Amsterdam, pp 431-461

76. Cozar A, Echevarria F, Ignacio Gonzalez-Gordillo J, Irigoien X, Ubeda B, Hernandez-Leon S, Palma AT, Navarro S, Garcia-deLomas J, Ruiz A, Fernandez-de-Puelles ML, Duarte CM (2014) Plastic debris in the open ocean. Proc Natl Acad Sci U S A 111(28):10239-10244. https://doi.org/10.1073/pnas.13147 05111

77. Cozar A, Sanz-Martin M, Marti E, Gonzalez-Gordillo Jl, Ubeda B, Galvez JA, Irigoien X, Duarte CM (2015) Plastic accumulation in the Mediterranean sea. PLoS One 10(4):e0121762. https://doi. org/10.1371/journal.pone.0121762

78. Ter Halle A, Ladirat L, Gendre X, Goudouneche D, Pusineri C, Routaboul C, Tenailleau C, Duployer B, Perez E (2016) Understanding the fragmentation pattern of marine plastic debris. Environ Sci Technol 50(11):5668-5675. https://doi.org/10.1021/ acs.est.6b00594

79. Araujo CF, Nolasco MM, Ribeiro AMP, Ribeiro-Claro PJA (2018) Identification of microplastics using Raman spectroscopy: latest developments and future prospects. Water Res 142:426440. https://doi.org/10.1016/j.watres.2018.05.060

80. Bergmann M (2015) Marine anthropogenic litter. Springer, Cham

81. Harrison JP, Ojeda JJ, Romero-González ME (2012) The applicability of reflectance micro-Fourier-transform infrared spectroscopy for the detection of synthetic microplastics in marine sediments. Sci Total Environ 416:455-463. https://doi. org/10.1016/j.scitotenv.2011.11.078

82. Löder MGJ, Kuczera M, Mintenig S, Lorenz C, Gerdts GJEC (2015) Focal plane array detector-based micro-Fourier-transform infrared imaging for the analysis of microplastics in environmental samples. Environ Chem 12(5):563-581. https://doi. org/10.1071/EN14205

83. Oßmann BE, Sarau G, Holtmannspötter H, Pischetsrieder M, Christiansen SH, Dicke W (2018) Small-sized microplastics and pigmented particles in bottled mineral water. Water Res 141:307-316. https://doi.org/10.1016/j.watres.2018.05.027

84. Strungaru S-A, Jijie R, Nicoara M, Plavan G, Faggio C (2019) Micro- (nano) plastics in freshwater ecosystems: abundance, toxicological impact and quantification methodology. Trends Anal Chem 110:116-128. https://doi.org/10.1016/j. trac.2018.10.025

85. Danopoulos E, Twiddy M, Rotchell JM (2020) Microplastic contamination of drinking water: a systematic review. PLoS One 15(7):e0236838. https://doi.org/10.1371/journal.pone.02368 38

86. Cannon SME, Lavers JL, Figueiredo B (2016) Plastic ingestion by fish in the Southern Hemisphere: a baseline study and review of methods. Mar Pollut Bull 107(1):286-291. https:// doi.org/10.1016/j.marpolbul.2016.03.057

87. Dehaut $A$, Cassone $A-L$, Frère $L$, Hermabessiere $L$, Himber $C$, Rinnert $E$, Rivière $G$, Lambert $C$, Soudant $P$, Huvet A, Duflos $G$, Paul-Pont I (2016) Microplastics in seafood: benchmark protocol for their extraction and characterization. Environ Pollut 215:223-233. https://doi.org/10.1016/j.envpol.2016.05.018

88. Filella M (2015) Questions of size and numbers in environmental research on microplastics: methodological and conceptual aspects. Environ Chem 12(5):527-538. https://doi.org/10.1071/ en15012

89. Hermsen E, Mintenig SM, Besseling E, Koelmans AA (2018) Quality criteria for the analysis of microplastic in biota samples: a critical review. Environ Sci Technol 52(18):10230-10240. https ://doi.org/10.1021/acs.est.8b01611
90. Hidalgo-Ruz V, Gutow L, Thompson RC, Thiel M (2012) Microplastics in the marine environment: a review of the methods used for identification and quantification. Environ Sci Technol 46(6):3060-3075. https://doi.org/10.1021/es2031505

91. Hong SH, Shim WJ, Hong L (2017) Methods of analysing chemicals associated with microplastics: a review. Anal Methods 9(9):1361-1368. https://doi.org/10.1039/c6ay02971j

92. Kedzierski M, Villain J, Falcou-Prefol M, Kerros ME, Henry M, Pedrotti ML, Bruzaud S (2019) Microplastics in Mediterranean sea: a protocol to robustly assess contamination characteristics. PLoS One 14(2):-e0212088. https://doi.org/10.1371/journ al.pone.0212088

93. Li J, Liu H, Paul Chen J (2018) Microplastics in freshwater systems: a review on occurrence, environmental effects, and methods for microplastics detection. Water Res 137:362-374. https://doi.org/10.1016/j.watres.2017.12.056

94. Mai L, Bao LJ, Shi L, Wong CS, Zeng EY (2018) A review of methods for measuring microplastics in aquatic environments. Environ Sci Pollut Res 25(12):11319-11332. https://doi.org/10.1007/ s11356-018-1692-0

95. Miller ME, Kroon FJ, Motti CA (2017) Recovering microplastics from marine samples: a review of current practices. Mar Pollut Bull 123(1-2):6-18. https://doi.org/10.1016/j.marpo Ibul.2017.08.058

96. Shim WJ, Hong SH, Eo SE (2017) Identification methods in microplastic analysis: a review. Anal Methods 9(9):1384-1391. https://doi.org/10.1039/c6ay02558g

97. Kase R, Korkaric M, Werner I, Ågerstrand M (2016) Criteria for reporting and evaluating ecotoxicity data (CRED): comparison and perception of the Klimisch and CRED methods for evaluating reliability and relevance of ecotoxicity studies. Environ Sci Eur 28(1):7. https://doi.org/10.1186/s12302-016-0073-x

98. Kentin E (2018) Restricting microplastics in the European Union: process and criteria under REACH. Eur Phys J Plus 133(133):425. https://doi.org/10.1140/epjp/i2018-12228-2

99. Klimisch HJ, Andreae M, Tillmann U (1997) A systematic approach for evaluating the quality of experimental toxicological and ecotoxicological data. Regul Toxicol Pharmacol 25(1):1-5. https://doi.org/10.1006/rtph.1996.1076

100. WHO (2012) Guideline: sodium intake for adults and children. World Health Organization, Geneva

101. EFSA NDA (2019) Dietary reference values for sodium. EFSA J 17(9):e05778. https://doi.org/10.2903/j.efsa.2019.5778

102. U.S. Department of Health and Human Services, U.S. Department of Agriculture (2015) 2015-2020 Dietary guidelines for Americans. Office of Disease Prevention and Health Promotion, Washington, DC

103. WHO (2020) Salt reduction; key facts. World Health Organization. https://www.who.int/news-room/fact-sheets/detail/saltreduction

104. Peixoto D, Pinheiro C, Amorim J, Oliva-Teles L, Guilhermino L, Vieira MN (2019) Microplastic pollution in commercial salt for human consumption: a review. Estuar Coast Shelf Sci 219:161168. https://doi.org/10.1016/j.ecss.2019.02.018

105. Plastics Europe (2008) The compelling facts about plastics. An analysis of plastics production, demand and recovery for 2006 in Europe. Plastics Europe, Brussels

106. Plastics Europe (2017) Plastics: the Facts 2017: an analysis of European plastics production, demand and waste data. Plastics Europe, Brussels

107. Plastics Europe (2018) Plastics - the Facts 2018; an analysis of European plastics production, demand and waste data. Plastics Europe, Brussels

108. Plastics Europe (2019) Plastics - the Facts 2019; an analysis of European plastics production, demand and waste data. Plastics Europe, Brussels 
109. Schwabl P, Köppel S, Königshofer P, Bucsics T, Trauner M, Reiberger T, Liebmann B (2019) Detection of various microplastics in human stool: a prospective case series. Ann Intern Med 171(7):453-457. https://doi.org/10.7326/M19-0618

110. Bucci K, Tulio M, Rochman CM (2020) What is known and unknown about the effects of plastic pollution: a meta-analysis and systematic review. Ecol Appl 30(2):e02044. https://doi. org/10.1002/eap.2044

111. Mishra P, Vinayagam S, Duraisamy K, Patil SR, Godbole J, Mohan A, Mukherjee A, Chandrasekaran N (2018) Distinctive impact of polystyrene nano-spherules as an emergent pollutant toward the environment. Environ Sci Pollut Res Int 26:1537-1547. https ://doi.org/10.1007/s11356-018-3698-z

112. Schirinzi GF, Perez-Pomeda I, Sanchis J, Rossini C, Farre M, Barcelo D (2017) Cytotoxic effects of commonly used nanomaterials and microplastics on cerebral and epithelial human cells. Environ Res 159:579-587. https://doi.org/10.1016/j.envre s.2017.08.043

113. Wright SL, Kelly FJ (2017) Plastic and human health: a micro issue? Environ Sci Technol 51(12):6634-6647. https://doi. org/10.1021/acs.est.7b00423

114. Wallace C (2015) HACCP a food industry briefing, 2nd edn. Wiley-Blackwell, Chichester, UK

115. Avio CG, Gorbi S, Milan M, Benedetti M, Fattorini D, d'Errico G, Pauletto M, Bargelloni L, Regoli F (2015) Pollutants bioavailability and toxicological risk from microplastics to marine mussels. Environ Pollut 198:211-222. https://doi.org/10.1016/j.envpo I.2014.12.021

116. Nelms SE, Galloway TS, Godley BJ, Jarvis DS, Lindeque PK (2018) Investigating microplastic trophic transfer in marine top predators. Environ Pollut 238:999-1007. https://doi.org/10.1016/j. envpol.2018.02.016

117. Ribeiro F, Garcia AR, Pereira BP, Fonseca M, Mestre NC, Fonseca TG, Ilharco LM, Bebianno MJ (2017) Microplastics effects in Scrobicularia plana. Mar Pollut Bull 122(1-2):379-391. https ://doi.org/10.1016/j.marpolbul.2017.06.078

118. Setala O, Norkko J, Lehtiniemi M (2016) Feeding type affects microplastic ingestion in a coastal invertebrate community.
Mar Pollut Bull 102(1):95-101. https://doi.org/10.1016/j.marpo Ibul.2015.11.053

119. Sussarellu $R$, Suquet $M$, Thomas $Y$, Lambert $C$, Fabioux $C$, Pernet MEJ, Le Goic N, Quillien V, Mingant C, Epelboin Y, Corporeau C, Guyomarch J, Robbens J, Paul-Pont I, Soudant P, Huvet A (2016) Oyster reproduction is affected by exposure to polystyrene microplastics. Proc Natl Acad Sci U S A 113(9):2430-2435. https://doi.org/10.1073/pnas.1519019113

120. Magrì $D$, Sánchez-Moreno $P$, Caputo $G$, Gatto $F$, Veronesi $M$, Bardi G, Catelani T, Guarnieri D, Athanassiou A, Pompa PP (2018) Laser ablation as a versatile tool to mimic polyethylene terephthalate nanoplastic pollutants: characterization and toxicology assessment. ACS Nano 12(8):7690-7700. https:// doi.org/10.1021/acsnano.8b01331

121. EFSA (2018) Emerging risks identification on food and feed - EFSA. EFSA J 16(7):e05359. https://doi.org/10.2903/j. efsa.2018.5359

122. EFSA (2019) European Food Safety Authority; The four steps of risk assessment. https://www.efsa.europa.eu/en/interactiv e_pages/riskassessment/RiskAssessment. Accessed 12 Feb 2019

123. FAO, WHO (2009) Principles and methods for the risk assessment of chemicals in food: Environmental Health Criteria 240. Food and Agriculture Organization of the United Nations and the World Health Organization, Stuttgart, , Germany

124. FDA (2002) U.S. Food and Drug Administration. A Report by the CFSAN Risk Analysis Working Group; Initiation and conduct of all "major" risk assessments within a risk analysis framework. https://www.fda.gov/Food/FoodScienceResearch/RiskSafety Assessment/ucm475127.htm\#parti. Accessed 15 Feb 2019

125. WHO, IPCS (2005) Principles of characterizing and applying human exposure models. World Health Organization, Geneva

Publisher's Note Springer Nature remains neutral with regard to jurisdictional claims in published maps and institutional affiliations. 